\title{
Comparison of Dioxin Destruction in the Fly Ash and Froths under Microwave Irradiation
}

\author{
Han-Qiao Liu ${ }^{1 *}$, Tong-Tong Zeng ${ }^{1}$, Guo-Xia Wei ${ }^{2}$, Rui Zhang ${ }^{1}$, Fang Liu ${ }^{1}$, Hao Wang ${ }^{1}$ \\ ${ }^{1}$ School of Science, Tianjin Chengjian University, Tianjin 300384, China \\ ${ }^{2}$ School of Energy and Safety Engineering, Tianjin Chengjian University, Tianjin, 300384 China
}

\begin{abstract}
The objective of this study was to check the feasibility to treat medical waste incinerator (MWI) fly ash directly through microwave irradiation. The destruction efficiency of dioxins in MWI fly ash and in its froth products after flotation was compared in the air/nitrogen $\left(\mathrm{N}_{2}\right)$ atmosphere. Results demonstrated that the dioxin destruction effect was better in a $\mathrm{N}_{2}$ atmosphere than that in an air atmosphere. And the total dioxin mass destruction efficiency of fly ash and the froths were $55.4 \%$ and $95.6 \%$ in the air atmosphere, while their values were $65.0 \%$ and $98.4 \%$ in the $\mathrm{N}_{2}$ atmosphere, respectively. The vaporisation ratio of dioxins in MWI fly ash was up to $10.2 \%$ after 9 min $\mathrm{N}_{2}$ irradiation. Furthermore, dechlorinating reactions of dioxins would occur when MWI fly ash was treated in $\mathrm{N}_{2}$ atmosphere. Therefore, microwave-absorbing additives should be used to improve the decomposition of dioxins because of MWI fly ash containing less carbon constituents than the froths.
\end{abstract}

Keywords: Fly ash; Microwave treatment; Dioxins; Destruction; Froths.

\section{INTRODUCTION}

Incineration has become one of the major methods for treatment of medical wastes, due to its advantages in terms of volume reduction, energy recovery, pathogen elimination and chemical-toxicity destruction (Hsieh et al., 2018a). Organic pollutants such as polycyclic aromatic hydrocarbons (PAHs), polychlorinated biphenyl (PCBs), and polybrominated diphenyl ethers (PBDEs), and polychlorinated dibenzo- $p$-dioxins and dibenzofurans (PCDD/Fs) were generated during incineration were controlled stringently due to their degradation resistance and hypertoxicity, especially for dioxins, which can cause a wide range of health effects in the immune, endocrine, nervous and reproductive systems of humans and animals. (Chao et al., 2014; Tzanakos et al., 2014; Cheruiyot et al., 2015; Lee et al., 2016; Hung et al., 2018; Tsai et al., 2018). Chlorine content in medical waste has reached $4.5 \%-7.5 \%$ due to the use of polyvinyl chloride plastic and $\mathrm{NaCl}$ in medical treatment, and it usually plays a major role in the formation of dioxins during medical waste incineration (MWI) process, leads to more dioxins be formed (Wang et al., 2003; Xie et al., 2013). The mean dioxin emission factor of the medical waste incinerator (MWI) (20.1 ng I-TEQ $\mathrm{kg}^{-1}$

\footnotetext{
* Corresponding author.

E-mail address: lhqlkx@126.com
}

waste) was approximately 210 times of magnitude higher than that of municipal solid waste incinerators (MSWI) (0.0939 ng I-TEQ kg-1 waste) (Chen et al., 2014; Han et al., 2017). $90 \%$ of the dioxins produced in incinerators were effectively captured by powder activated carbon (PAC), removed through bag filter and then transferred into MWI fly ash (Cheruiyot et al., 2016; Zhan et al., 2018). Researchers reported that MWI fly ash has a higher content of 2-3 orders for magnitude dioxins than that in MSWI fly ash (Hsieh et al., 2018b). MWI fly ash has been identified as hazardous waste in many countries. MWI fly ash also contains carbon constituents including powder activated carbon (PACs) and unburned carbon, which was found to be a dioxin enrichment of source (Liu et al., 2017a). In our previous study, a novel flotation technique was developed, which could separate the dioxins and carbon constituents from MWI fly ash simply and economically (Liu et al., 2013). Most of the dioxins and carbon constituents were transferred into the froth product, and chlorides were simultaneously washed out from MWI fly ash (Liu et al., $2017 \mathrm{~b}$ ). Thus, it is necessary to develop effective technology to thorough decompose the dioxins in the froths.

Thermal treatment is one of the most common methods to decompose the dioxins at approximately $300^{\circ} \mathrm{C}$ in inert gas conditions to dechlorination and hydrogenation promising, because dioxins are instability in the high temperature (Mizukoshi et al., 2007; Zhu et al., 2017). Wang et al. (2006) found that the detoxification efficiency of dioxins in MSWI fly ash was above $90 \%$ in nitrogen $\left(\mathrm{N}_{2}\right)$ atmosphere 
and $300^{\circ} \mathrm{C}$ for $2 \mathrm{~h}$. Wu et al. (2011) reported that fly ash constituent is a crucial factor, which can influence or dominate the destruction efficiency of dioxins in fly ash. In addition, another effective method is thermal treatment at temperature exceeding $450^{\circ} \mathrm{C}$ in oxidative conditions (Hung et al., 2013). Lundin et al. (2011) noted that the total dioxin content in fly ash was reduced significantly after treatment at $500^{\circ} \mathrm{C}$ in air because of degradation rather than dechlorination. However, in some cases, a high risk of de novo synthesis may be incurred, which leads to the reformation of dioxins (Lundin et al., 2011). Wang et al. (2012) reported that the dioxin content in MWI fly ash increased from 6.2 to $401.0 \mathrm{ng}$ I-TEQ $\mathrm{g}^{-1}$ when fly ash was treated at $850^{\circ} \mathrm{C}$ in air atmosphere without adding $\mathrm{CaO}$ (I-TEQ is the international toxic equivalent quantity. Melting at over $1300^{\circ} \mathrm{C}$ is recommended to decompose dioxins in fly ash, the OCDD and OCDF in slag product was high (Kim et al., 2005; Wang et al., 2006; Lin et al., 2011). The PCDD/Fs TEQ decomposition efficiency can exceed $99 \%$ after the plasma melting process, but it consumes considerable energy (Pan et al. 2013). Rafalp et al. (2001) treat fly ash by reburning treatment in the combustion chamber, more than $99 \%$ of the PCDD/Fs in the fly ash could be decomposed. In our previous study, the froths obtained after flotation were treated by reburning in the combustion chamber, the total dioxin mass destruction efficiency of which is more than $98 \%$ at temperatures higher than $1000^{\circ} \mathrm{C}$ (Wei et al., 2017). However, if traditional heat treatment in air is used to treat the froths, resources will be wasted because large amounts of PAC in the froths are burnt instead of being reused.

Compared with conventional heating treatment, microwave heating is environmentally friendly and possesses additional advantages of high heating rates, selective heating, less treating time and lower energy consumption (Dehdashti et al., 2011; Antonetti et al., 2015; Rivas et al., 2015). Researchers have found that organic pollutants can be decomposed by microwave heating (Liu et al., 2008; Wu et al., 2008; Lin et al., 2010; Huang et al., 2011; Lin et al., 2013; Antonetti et al., 2016). Meanwhile, activated carbon can adsorb and converse microwave energy into thermal energy due to its excellent dielectric properties (Jou et al., 2009). Elimination of organic pollutants under microwave irradiation integrated with activated carbon addition was previously reported (Dehdashti et al., 2011). "Hotspots" would be formed on the activated carbon surfaces during microwave irradiation, the temperature of these "hotspots" is particularly higher than that of other places. Thus, chemical reactions might occur easily at the high temperature, which could accelerate the elimination of organic pollutants (Zhang et al., 2007, 2009). Dehdashti reported that the 'temperature-rise' phenomenon of activated carbon under microwave irradiation depended on microwave power and the nature of adsorbent in the sample (Dehdashti et al., 2011). Redox atmosphere may also affect the organic pollutant decomposition because PAC is easily oxidised and combusted in suitable atmosphere (Amankwah et al., 2005). Jou et al. (2009) concluded that organic pollutants that adsorbed on the surface of the PAC were degraded under microwave irradiation because of microwave-assisted oxidation. Our previous study found that the total mass destruction efficiency of the PCDD/Fs in the froths could reached above $99 \mathrm{wt} \%$ with a microwave incident power of $2100 \mathrm{~W}$ for $7 \mathrm{~min}$ in $\mathrm{N}_{2}$ atmosphere, because PAC in the froths can work as microwave absorbent (Wei et al., 2017).

Using microwave heating to treat incinerator fly ash is an innovative approach. In recent years, microwave sintering has been employed successfully on the stabilisation of heavy metals in MSWI fly ash. Chou et al. (2009) found that a long microwave sintering time of fly ash corresponded to a higher stabilisation efficiency of heavy metals. Besides, soluble chlorides in MSWI fly ash could affect the sintering effect (Lin et al., 2018). However, MSWI fly ash treatment by microwave heating usually need microwave absorbent or microwave-absorbing crucible because of its low carbon content (Chou et al., 2009; Chou et al., 2013).

Comparing with MSWI fly ash, MWI fly ash contains higher content of carbon constituents $(>11 \%)$ due to PAC injection in the air pollution control devices (APCDs) (Liu et al., 2013). However, few studies have questioned whether microwave sintering could directly detoxify the dioxins in MWI fly ash and whether its peculiar high carbon content might facilitate PCDD/F decomposition. Compared with the froths, relatively less carbon constituents and even more chlorides in the MWI fly ash might affect the detoxication of dioxins. The objective of this study was to investigate the feasibility to treat MWI fly ash directly by microwave. Meanwhile, the destruction effect of dioxins in raw fly ash and its froth products in different atmosphere were compared.

\section{MATERIALS AND METHODS}

\section{Materials}

$25 \mathrm{~kg}$ of fly ash sample used in this study was obtained from a $20 \mathrm{t} \mathrm{d}^{-1}$ gyration kiln incinerator at a MWI centre in northern China. The incinerator was equipped with a PAC sprayer device and bag filters as APCDs for dioxin management. The fresh and dry fly ash sample was collected from the hopper of a bag filter. The ash sample was collected over a 7-day period and homogenized and passed through a sieve of 20 meshes, and then was dried at $105^{\circ} \mathrm{C}$ for $24 \mathrm{~h}$ to further analyse.

$15 \mathrm{~kg}$ of fly ash sample was treated by column flotation, the flotation experimental apparatus and operating conditions were the same as those of our previous study (Liu et al., 2013). The suitable flotation conditions were $0.05 \mathrm{~kg} \mathrm{~L}^{-1}$ of slurry concentration, $12 \mathrm{~kg} \mathrm{t}^{-1}$ of kerosene, $3 \mathrm{~kg} \mathrm{t}^{-1}$ of froths, and a $0.06 \mathrm{~m}^{3} \mathrm{~h}^{-1}$ air flow rate. The froths were carefully vacuum-filtered, dried, weighed, and stored. Loss on ignition (LOI) analysis was used to determine the carbon content in the raw fly ash and froth product, respectively, as shown in Table 1. Chemical composition of fly ash was measured by MXF-2400 X-Ray Fluorescence Spectrometer. PAC sample that had been injected into the APCDs of the incinerator was obtained from the PAC storage tank at the waste incineration plant. The PAC is made from a coconut shell. 
Table. 1. Chemical composition and LOI of raw fly ash and the froths (\%).

\begin{tabular}{|c|c|c|c|c|c|c|c|c|c|c|c|c|c|}
\hline Sample & $\mathrm{SiO}_{2}$ & $\mathrm{CaO}$ & $\mathrm{Al}_{2} \mathrm{O}_{3}$ & $\mathrm{Fe}_{2} \mathrm{O}_{3}$ & $\mathrm{MgO}$ & $\mathrm{K}_{2} \mathrm{O}$ & $\mathrm{Na}_{2} \mathrm{O}$ & $\mathrm{SO}_{3}$ & $\mathrm{Cl}$ & $\mathrm{P}_{2} \mathrm{O}_{5}$ & $\mathrm{TiO}_{2}$ & $\mathrm{~F}$ & LOI \\
\hline $\mathrm{Ra}$ & 17.13 & 24.42 & 2.85 & 1.78 & 1.8 & 2.8 & 15.2 & 6.37 & 20.43 & 1.06 & 1.34 & 2.59 & 11.1 \\
\hline Froths & 32.45 & 38.56 & 5.33 & 3.40 & 3.28 & 1.08 & 0.05 & 6.09 & 2.85 & 1.35 & 2.24 & 0.75 & 56.4 \\
\hline
\end{tabular}

\section{Methods}

The raw fly ash, froths and PAC samples were pelleted for $5 \mathrm{~s}$ with a hydraulic press at a maximum pressure of $50 \mathrm{MPa}$. A water solution of $3 \mathrm{wt} \%$ polyvinyl alcohols was then added into the samples at a $5 \mathrm{wt} \%$ concentration to bind the pressed particles. Subsequently, pellets with a height of $15 \mathrm{~mm}$ and diameter of $10 \mathrm{~mm}$ were dried at $110^{\circ} \mathrm{C}$ for $3 \mathrm{~h}$.

Then, these pellets were sintered in a high-temperature laboratory microwave oven (HAMilab-V3000, Synotherm Corporation, Changsha, China). A schematic diagram of the laboratory microwave oven is shown in Fig. 1. The power was varied from 0 to $3000 \mathrm{~W}$ and the magnetron operates at a frequency of $2450 \mathrm{MHz}$. The furnace was composed of a double-layer, water-cooled, vacuum-sealed, stainless steel chamber attached to vacuum and gas entrance systems. During this experiment, the pellets were placed in a microwave transparent quartz crucible with the following dimensions: the height of $45 \mathrm{~mm}$, the diameter of $50 \mathrm{~mm}$, and the thickness of $2 \mathrm{~mm}$. During each experiment, eight pellets were placed inside the alumina crucible. The crucible and its contents were positioned in the center of the base of the microwave chamber, on a microwave transparent alumina platform that acted as an insulator. The alumina insulation board was a poor microwave absorber. During the experiment, radiation was continuous and uniformity was maintained to provide heat to each pellet under consideration.

Temperature measurement in microwave field is regarded crucial for microwave treatment. In view of that PAC sample is relatively uniform; the infrared pyrometer was used to measure the surface temperature of PAC pellet on the top layer in a microwave field (Yuen et al., 2009). Air or $\mathrm{N}_{2}$ flowed through the microwave oven at a flow rate of $3 \mathrm{~L} \mathrm{~min}^{-1}$ to provide an oxidation or inert atmosphere, respectively, and to evacuate any volatile products. According to the preliminary results, the processing time could influence the experiment. Initially, the microwave power was stabilized at $1800 \mathrm{~W}$, and processing for 5,7 , and 9 min were used in $\mathrm{N}_{2}$ atmosphere. When the atmosphere was changed, the microwave power and processing time were stabilised at $1800 \mathrm{~W}$ and $9 \mathrm{~min}$, respectively. The specimens were then cooled in the furnace.

In each test run, the treated sample was also collected, grinded and thoroughly mixed after cooled. Samples collected were stored in a refrigerator before analysis. The exhaust gas generated from microwave treatment process was introduced into XAD-2 polymeric resin and a toluene absorber bottle to examine the evaporation of dioxins. After each test run, XAD-2, toluene and rinsed solvent (flushing the reactor and tube with toluene) was collected and mixed as one sample to follow the standard PCDD/F analysis procedures.

The content of 17 toxic dioxin congeners $(2,3,7,8$ substituented) were analysed using isotope dilution highresolution gas chromatography/high-resolution mass spectrometry. The PCDD/F content analysis was performed following the method used in our previous report (Wei et al., 2016). Analytical results for the 17 specific congeners used to calculate the I-TEQ are reported. The PCDD/F

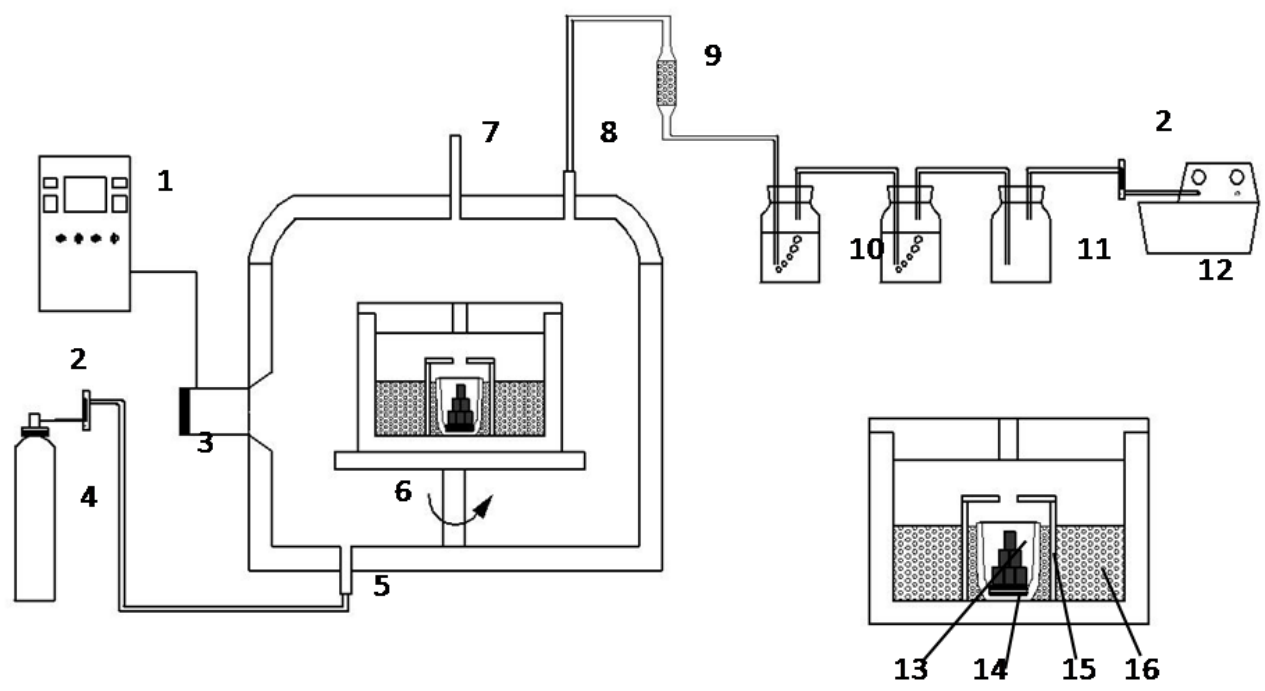

1: Control system; 2: Rotameter; 3: Magnetron; 4: Air/Nitrogen; 5: Gas inlet; 6: Electric turntable; 7: Infrared pyrometer; 8: Gas outlet; 9: XAD -2 resin; 10: Toluene absorber bottle; 11: Silica gel bottle; 12: Vacuum pump; 13: Sample; 14: Graphite plate; 15: Alumina crucible; 16: Alumina platform.

Fig. 1. Schematic diagram of the microwave laboratory oven. 
destruction efficiency was calculated for both gaseous dioxins vaporised or desorbed from the samples (raw fly ash or froths) during microwave treatment and adsorbed by XAD-2 resin, and for solid-phase dioxins that remained on the treated samples. The vaporisation ratio was defined as the percentage of gaseous dioxins that were vaporised off or desorbed from the untreated samples. The destruction efficiency and vaporisation ratio of dioxins in raw fly ash or the froths were calculated as follows, respectively.

Destruction efficiency $=$

$[1-(($ Dioxin amount adsorbed by XAD-2 resin $)+($ Dioxin amount in the treated sample) $) /($ Dioxin amount in the untreated sample) $] \times 100 \%$

Vaporisation ratio $=$

((Amount of dioxins adsorbed by XAD-2 resin)/

(Amount of dioxins in the untreated sample) $) \times 100 \%$

\section{RESULTS AND DISCUSSION}

\section{Surface Temperature of PAC in the Microwave Field}

The behaviour of the PAC under microwave heating was evaluated by measuring the surface temperature of the PAC pellets in microwave field. Three replicates were made to obtain reliable data and the results were determined as the average of three measurement results. Fig. 2 illustrates the surface temperature of the PAC pellets in different atmospheres while being heated with microwaves incident power of $1800 \mathrm{~W}$. The temperature increased with time in a $\mathrm{N}_{2}$ atmosphere. After $5 \mathrm{~min}$, the rate of the temperature rise decreased, which has previously been attributed to energy insufficiency (Dehdashti et al., 2011). In an air atmosphere, the temperature increased again rapidly, and reached $860^{\circ} \mathrm{C}$, which was relatively higher than that in the $\mathrm{N}_{2}$ atmosphere. However, the sample temperature started to drop slowly after $7 \mathrm{~min}$ and dipped to a lower temperature than that when a $\mathrm{N}_{2}$ atmosphere was used after 9 min. This may be related to the dielectric properties of PAC. The dielectric loss factor of PAC initially increased sharply with the temperature rise. In an air atmosphere, the dielectric behaviour of PAC decreased because of partial oxidation or combustion. Most of the PAC was then consumed, which decreased its microwave coupling efficiency (Amankwah et al., 2005). The vast difference of heating curves in the $\mathrm{N}_{2}$ and air clearly suggested that the microwave absorption nature of PAC in air atmospheres was not identical after $9 \mathrm{~min}$.

\section{Influence of Processing Time on PCDD/F Destruction}

The total PCDD/F content in the raw fly ash and froths were 78.8 and $403.8 \mathrm{ng} \mathrm{g}^{-1}$, and the PCDD/Fs-I-TEQ were 5.6 and $29.0 \mathrm{ng}$ I-TEQ $\mathrm{g}^{-1}$, respectively (Fig. 3). The total PCDD/Fs-I-TEQ in the froths was more than 5 times of that in the raw fly ash. Our previous study demonstrated that the flotation process removed $>90 \%$ of dioxins during the transition from raw fly ash to froths (Liu et al., 2013). The distribution of $\mathrm{PCDD} / \mathrm{F}$ congeners in the froths was extremely similar to that in the raw fly ash. Most of the PCDDs came from HpCDDs and OCDDs, which are 7-Cl or 8-Cl PCDDs. Most of the PCDFs were TeCDFs, 1,2,3,4,7,8-HxCDFs, 2,3,4,6,7,8-HxCDFs, 1,2,3,4,6,7,8HpCDFs, and OCDFs. Flotation did not substantially alter the congener fingerprint of PCDD/Fs.

Fig. 4 illustrates the total mass destruction efficiency of dioxins in the raw fly ash and froths when different processing times were used in a $\mathrm{N}_{2}$ atmosphere. Fig. 5 shows the TEQ content of residual dioxins in the samples after microwave treatment. The destruction efficiency of both samples increased when the processing time was prolonged. For the raw fly ash, 34.6\%, 47.7\%, and $65.0 \%$ of total PCDD/F mass destruction efficiencies ere achieved when processing for 5,7 , and $9 \mathrm{~min}$, and the total TEQ content of dioxins decreased to $4.5,3.5$, and $1.6 \mathrm{ng} \mathrm{g}^{-1}$, respectively. When the same experiment was performed using the froths, the total dioxin mass destruction efficiencies after 5,7 , and 9 min of processing were $76.9 \%, 91.9 \%$, and $98.4 \%$, and the total TEQ content of dioxins decreased from

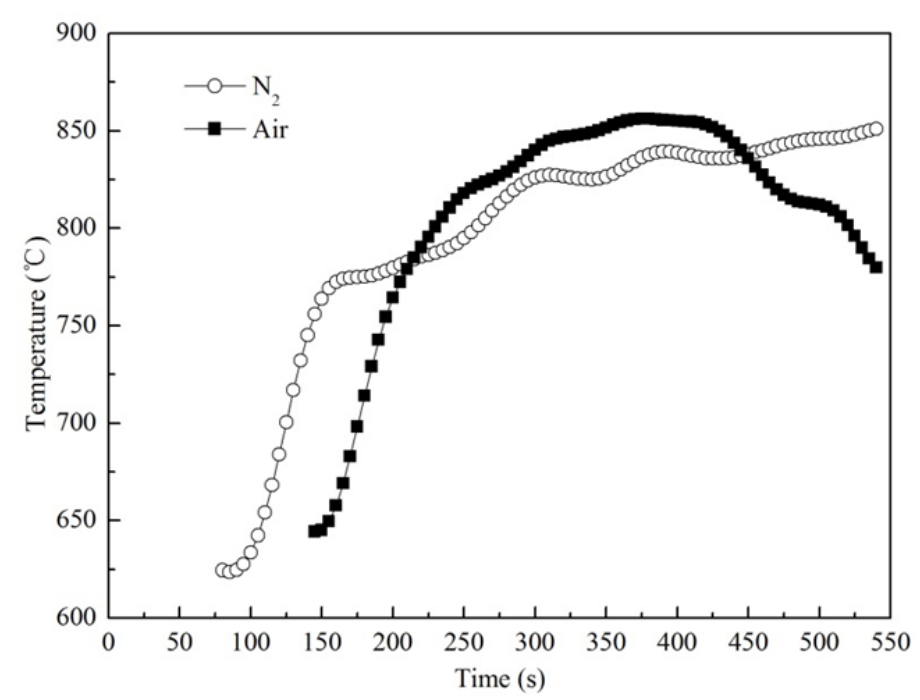

Fig. 2. Effect of the atmosphere on the temperatures rising courses of the surface of PAC tables. 


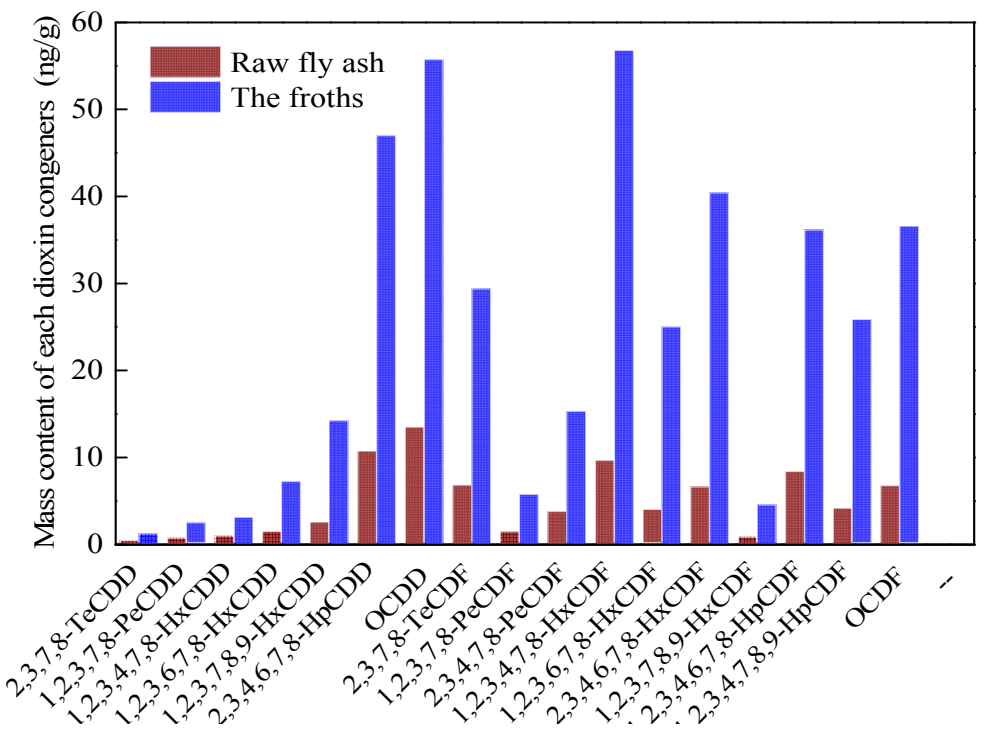

Fig. 3. Mass content of each dioxin congener for the raw fly ash and the froths.

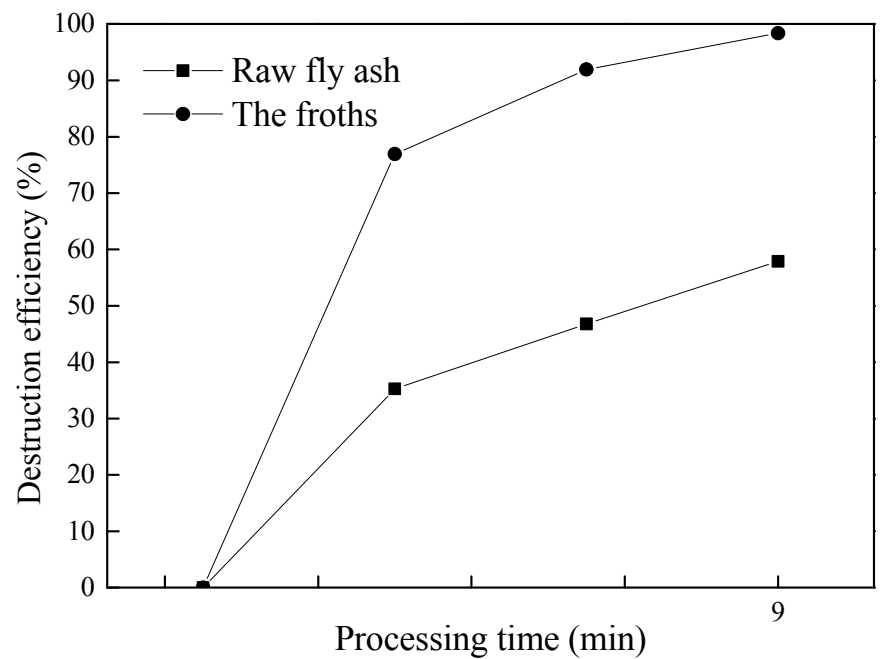

Fig. 4. Effect of processing times on total mass destruction efficiency of dioxins in the samples.

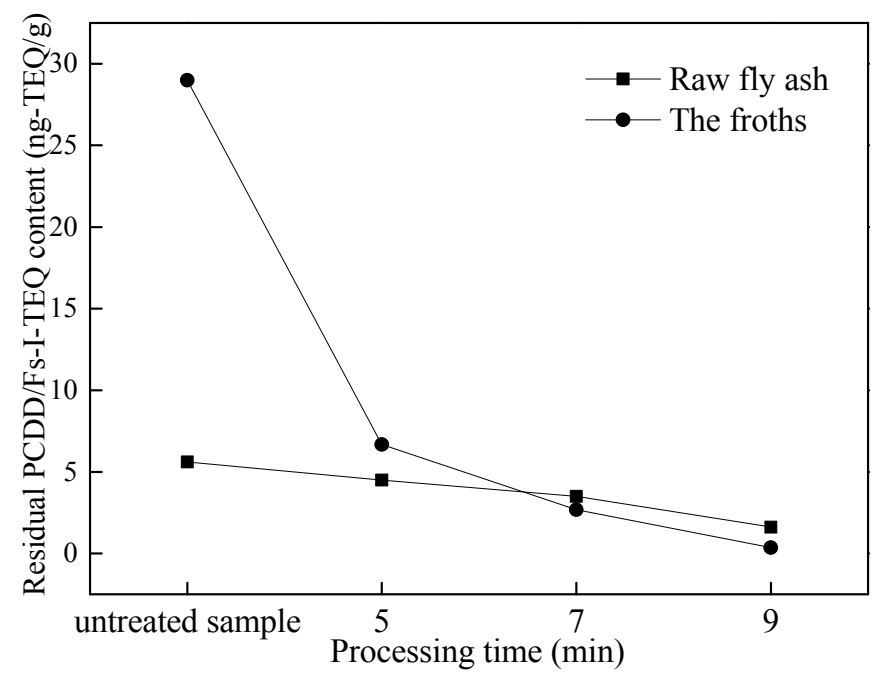

Fig. 5. Residual PCDD/Fs-I-TEQ in the samples after microwave treatment at different processing time. 
$29.0 \mathrm{ng} \mathrm{g}^{-1}$ to $6.7,2.7$, and $0.4 \mathrm{ng}$-TEQ $\mathrm{g}^{-1}$, respectively. Therefore, a long processing time enhanced the destruction efficiency. Moreover, compared with the duration of traditional thermal treatment (more than $0.5 \mathrm{~h}$ ) (Lundin et al., 2011; Wu et al., 2011; Hung et al., 2013), microwave treatment took less time to achieve a similar decomposition efficiency, which indicated that microwave treatment of the froths is an efficient treatment technology.

Although the initial dioxin content in the froths was higher than that in raw fly ash, the dioxin mass destruction efficiencies in the froths were higher after equal processing time. The results explained by the higher amount of PAC in the froths than that in the raw fly ash. The thermal mechanism of microwave heating of the samples could be as follows: (i) the uneven surfaces of PAC firstly absorbed and transformed microwave energy into heat at room temperature and then formed numerous "hot spots" in the froths (Dehdashti et al., 2011), leading to the adsorption of dioxins or rapid decomposition of the existed PAC; (ii) the local heating in the samples is not uniform, during which heat from the PAC raised the temperature of the pellets; (iii) the temperature of the pellets was high enough to allow chemical species such as $\mathrm{Fe}_{3} \mathrm{O}_{4}, \mathrm{Fe}_{2} \mathrm{O}_{3}, \mathrm{MnO}_{2}, \mathrm{MgO}$ and $\mathrm{TiO}_{2}$ to absorb and transform microwave energy into heat energy; and to remove the rest of dioxins in the samples (Chou et al., 2013). The froths absorbed more energy than that of the same amount in the raw fly ash because the content of PAC in the froths was high, and more "hotspots" were formed in it during the microwave treatment. The whole temperature of the froths was also enhanced within a short period, and thus the dioxin destruction efficiency in the froths enhanced compared with that in the raw fly ash. Therefore, high carbon content in the froths contributed to high destruction of dioxins.

Fig. 6 shows the effect of processing time on the distribution profiles of the 17 major dioxin congeners in MWI fly ash. The distributions of dioxin congeners in the treated samples were similar to those in raw fly ash. The initial contents of HpCDD, OCDD, TeCDF, 1,2,3,4,7,8HxCDF, 2,3,4,6,7,8-HxCDF, 1,2,3,4,6,7,8-HpCDF, and OCDF were high, which lead to those remaining content in the treated samples were also high. The homologue distribution of dioxins did not change obviously when processing time was extended, which indicated the reductions of dioxin levels under microwave treatment are caused not by dechlorination but mainly by decomposition or vaporisation of dioxins. This result is not consistent with the study conducted by Chang using microwave peroxide oxidation (MPO) treatment methods (Chang et al., 2013). They found the distribution of 17 major dioxin congeners shifted from highly chlorinated dioxins to low chlorinated dioxins after MPO treatment. The main reasons are intrinsic differences in molecular diffusion and reaction activity among dioxin congeners during MPO processing.

\section{Influence of Processing Time on Dioxin Evaporation}

Fig. 7 gives the vaporisation ratio of dioxins in the two samples on various processing times. Evaporation of dioxins from both raw fly ash and froths increased with the processing time increasing (up to a maximum of $9 \mathrm{~min}$ ). The amount of dioxins in the exhaust gas after $9 \mathrm{~min}$ of raw fly ash treatment was $10.2 \mathrm{wt} \%$ of the original amount. By studying the evaporation of dioxins during the reburning process of fly ash, Kobylecki et al. (2011) reported that the amount of evaporated dioxins in fly ash did not exceed $3 \mathrm{wt} \%$ by conventional heating treatment. Wu et al. (2011) discovered that the amount of dioxins desorbed to the gas phase increased with the heating temperature from $300^{\circ} \mathrm{C}$ to $400^{\circ} \mathrm{C}$.

The amount of dioxins in the exhaust gas after processing

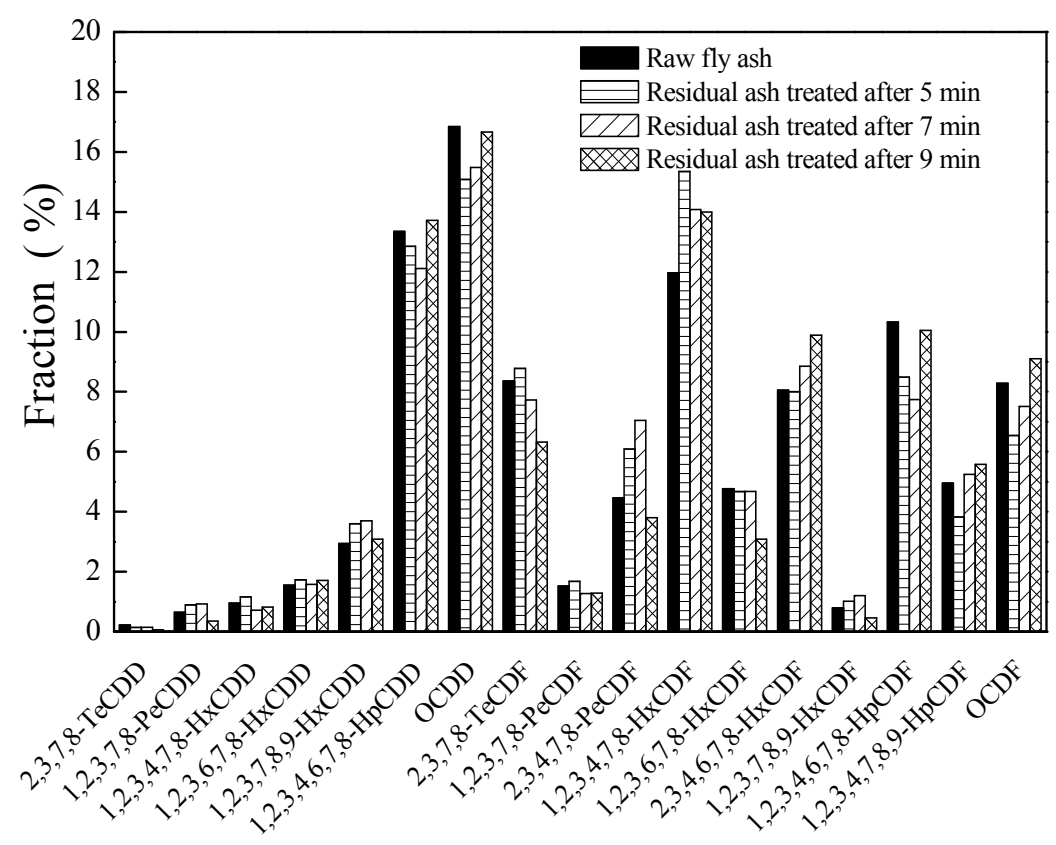

Fig. 6. Distribution profiles of 17 major dioxin congeners in the samples under different processing time. 


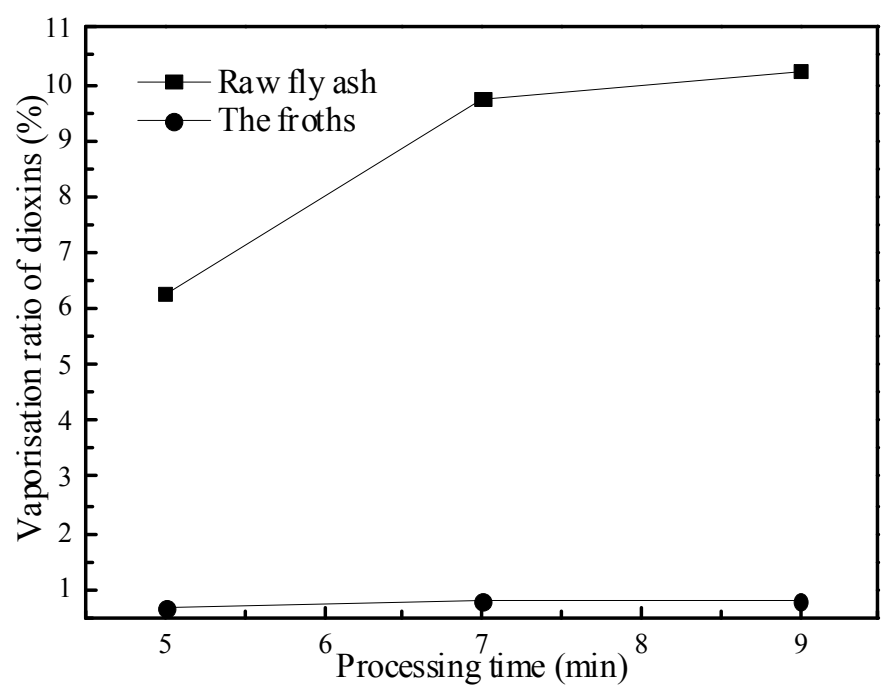

Fig. 7. Vaporisation ratio of dioxins in the samples at various processing times.

for $9 \mathrm{~min}$ was only $0.8 \mathrm{wt} \%$ of that in the untreated froths. Therefore, dioxins in the froths had mostly decomposed and just few evaporated into the exhaust gas. Compared with raw fly ash, the larger amount of PAC in the froths resulted in more effective microwave energy absorption, which initially caused a rapid increase of the overall temperature of the froths. Therefore, most of the dioxins in the froths were quickly decomposed, leaving few to be evaporated. Furthermore, PAC may have captured and decomposed gaseous phase dioxins and prolonged their escape time, making it possible for $\mathrm{PCDD} / \mathrm{F}$ destruction. The content of PAC in raw fly ash is not enough to support the decomposition of dioxins in a short time, which is easy to lead to dioxin volatilizations. Thus, addition of appropriate amount of microwave-absorbing medium is necessary.

\section{Effect of Atmosphere on Dioxin Destruction}

Fig. 8 displays the residual content of each dioxin congener in the samples (the raw fly ash and froths) after microwave treatment for $9 \mathrm{~min}$ in air $/ \mathrm{N}_{2}$ atmospheres. The remaining content of each dioxin congener in the two residual samples was higher in an air atmosphere compared with that in a $\mathrm{N}_{2}$ atmosphere. For the raw fly ash, the total mass dioxin destruction efficiency was $55.4 \%$ in an air atmosphere, $10 \%$ less than that in a $\mathrm{N}_{2}$ atmosphere. This is also lower than that reported by other studies on lowtemperature thermal treatment (Wu et al., 2011; Hung et al., 2013). For the froths, $95.6 \%$ and $98.4 \%$ of the dioxins were destroyed following treatment in air and $\mathrm{N}_{2}$ atmosphere, respectively.

The redox atmosphere used affects not only the microwave absorption characteristics of PAC in the samples but also the dioxin removal mechanisms. PAC is a hyperactive material which may have interaction with microwaves. The permittivity of the PAC was extremely high even at room temperature and increased rapidly with the temperature rise, which facilitated microwave absorption. In a $\mathrm{N}_{2}$ atmosphere, dioxins were desorbed, decomposed, and carbonised because of thermal effects. Not only the simple chemical bonds such as $\mathrm{C}-\mathrm{Cl}$ and $\mathrm{C}-\mathrm{C}$ were destroyed, but also the benzene rings were degraded quickly (Zhang et al., 2009). All these possible dioxin reactions (Eq. (3)) could occur. During microwave heating, PAC might serve as a catalyst of PCDD/Fs decomposition. And the catalytic action of the PAC might help the thermal decomposition of the PCDD/Fs in a relatively low temperature (Cha, 2001).

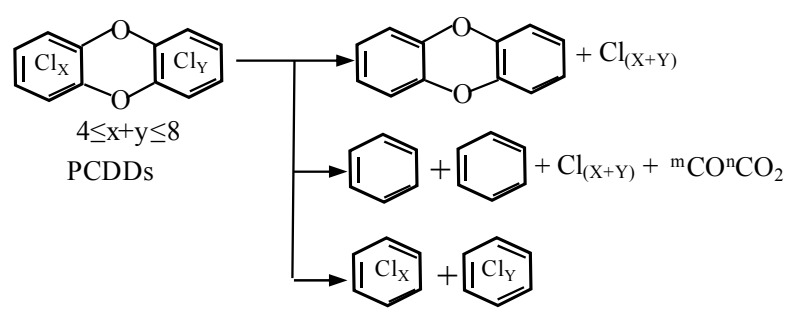

In an air atmosphere, however, PAC was easily oxidised and combusted and its permittivity would have thus decreased, which also limited its microwave absorption (Amankwah et al., 2005). Therefore, the total destruction efficiency of dioxins was lower in an air atmosphere compared with that in a $\mathrm{N}_{2}$ atmosphere. When oxygen was used, the process of dioxin removal was similar to the oxidation combustion of organic pollutants, for which decrease in decomposition also occurred (Zhang et al., 2009). When dioxins experienced a carbon-carbon bond rupture and oxidation reactions under microwave irradiation, $\mathrm{CO}_{2}, \mathrm{H}_{2} \mathrm{O}$, and simple inorganic ions were produced (Zhang et al., 2009). The reaction of Eq. (4) is considered to have occurred.

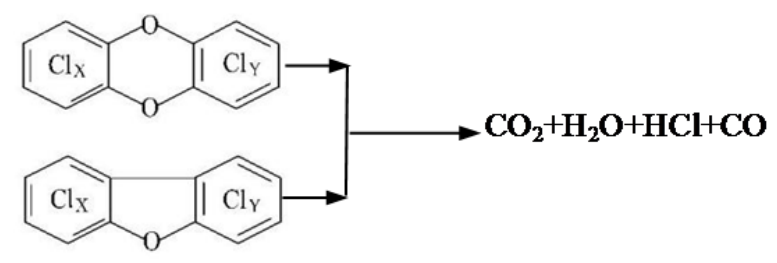




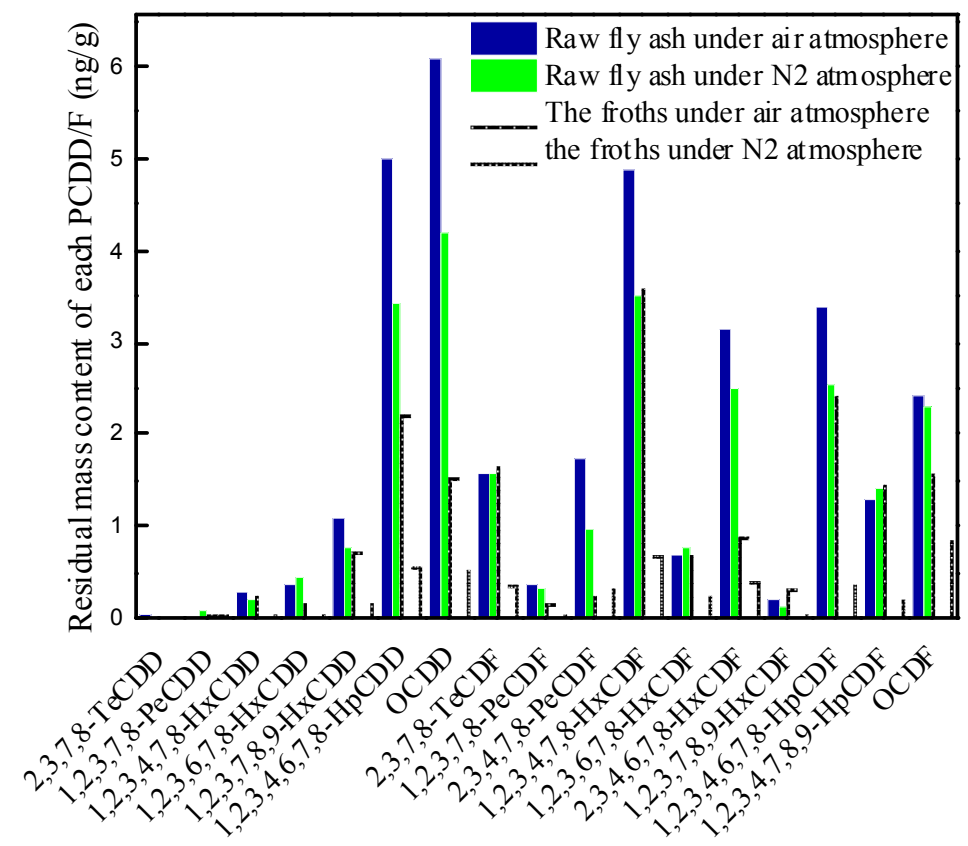

Fig. 8. Effect of the atmospheres on residual mass content of each PCDD/F congener in the samples.

\section{Effect of Atmosphere on Distribution of Dioxin Congeners in Exhaust Gas}

Fig. 9 shows the distribution profiles of 17 major dioxin congeners in the exhaust adsorption traps for 9 min of microwave treatment of the raw fly ash and froths in air and $\mathrm{N}_{2}$ atmospheres. As a whole, the distribution of dioxin congeners in four kinds of exhaust gas were similar to that in the raw material, HpCDDs, OCDDs, TeCDFs, 1,2,3,4,7,8HxCDFs, 2,3,4,6,7,8-HxCDFs, 1,2,3,4,6,7,8-HpCDFs, and OCDFs still showed higher peak of fraction. For the raw fly ash, the fraction of low chlorinated congeners, such as 2,3,7,8-TeCDF and 1,2,3,7,8-PeCDF, were obviously higher in $\mathrm{N}_{2}$ atmosphere than that in air atmosphere, and high chlorinated PCDD/Fs were relatively low. For froths, there was no obvious difference in the homologue distribution in gas phase of exhaust gas in air and $\mathrm{N}_{2}$ atmosphere.

Dioxins in flue gases were susceptible to volatilization, dechlorination or de novo synthesis during microwave irradiation of the fly ash or the froths. Volatilization of dioxins might happen at the initial stage of microwave heating, during which the overall temperature of the two kinds of samples increased slowly. Thus, small amount of dioxins might evaporate into gaseous phase. Wang et al. (2006) reported that dechlorination of dioxins generally occur in an oxygen-deficient atmosphere during conventional low-temperature treatment. Similarly, raw fly ash contains less carbonaceous matter, its overall temperature is relatively low at initial stage after microwave heating, during which dechlorination reaction might happen in $\mathrm{N}_{2}$ atmosphere. Fig. 10 shown that chlorination degree of dioxins in the gas phase of exhaust gas in $\mathrm{N}_{2}$ atmosphere is 6.27 , which is lower than that in raw fly ash (6.55). This also confirms the possibility of chlorination during this process. However, in air atmosphere, dioxin removal in raw fly ash might result in oxidation reactions rather than decomposition or dechlorination process. For froths, chlorination degrees in products were found to have no significant change in air or $\mathrm{N}_{2}$ atmosphere, which implies that contributors of dechlorination reactions were very litter during microwave heating. This is because that the froths contained with high content of PAC could quickly reached high temperature, which lead to more decomposition and less evaporation of dioxins.

The crucial elements of de novo synthesis are temperature, catalysis using carbon, chlorine, oxygen, and metals (especially $\mathrm{Cu}$ ) (Wang et al., 2012). Compared with the raw fly ash, the froths contained more carbon constituents, more copper and less chlorine. Residual carbon and PAC could provide basic organic material and the catalytic surface for dioxin formation (Kakuta et al., 2005; Chang et al., 2009). $\mathrm{Cu}$ is also essential for catalysing formation of dioxins. Therefore, high levels of $\mathrm{Cu}$ and carbon constituents in the froths might promote de novo synthesis of dioxins (Chin et al., 2012). The lack of chlorine in the froths, however, inhibited this de novo synthesis during microwave heating. Furthermore, high PAC content in the froths effectively raised its ability to absorb microwave energy and made the froths quickly past the temperature range of de novo synthesis of dioxins $\left(250-400^{\circ} \mathrm{C}\right)$ (Mizukoshi et al., 2007). Therefore, for the froths, dioxins should hardly form via de novo synthesis under microwave irradiation. For the raw fly ash with high levels of chlorine, a certain amount of $\mathrm{Cu}$, carbon constituents and the presence of oxygen easily led to the reformation of dioxins by de novo synthesis at the beginning of the microwave treatment. How the complex composition of the raw fly ash and froths precisely affect the de novo synthesis is unclear at present, given the discrepancies in the limited data available. Therefore, to judge whether de novo synthesis reactions occurs under microwave irradiation is difficult. 


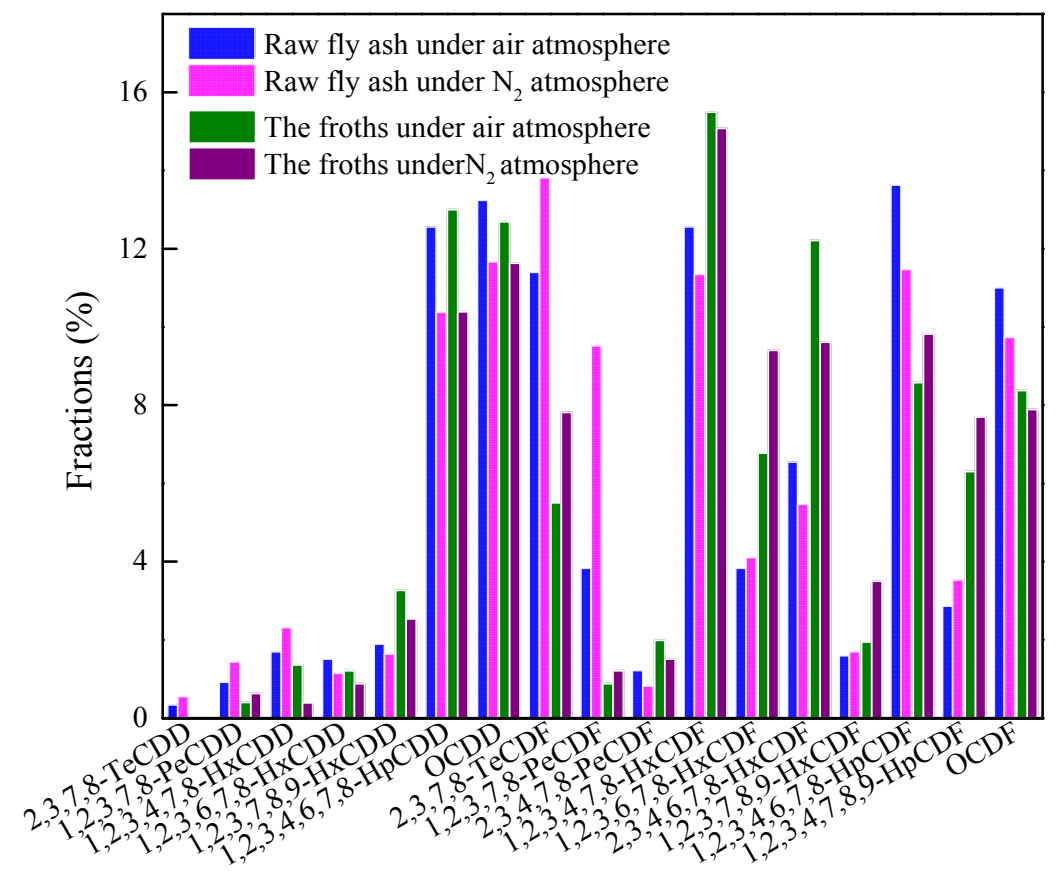

Fig. 9. Effect of the atmospheres on distribution of dioxin congeners in the exhaust gas after 9 min of microwave treatment.

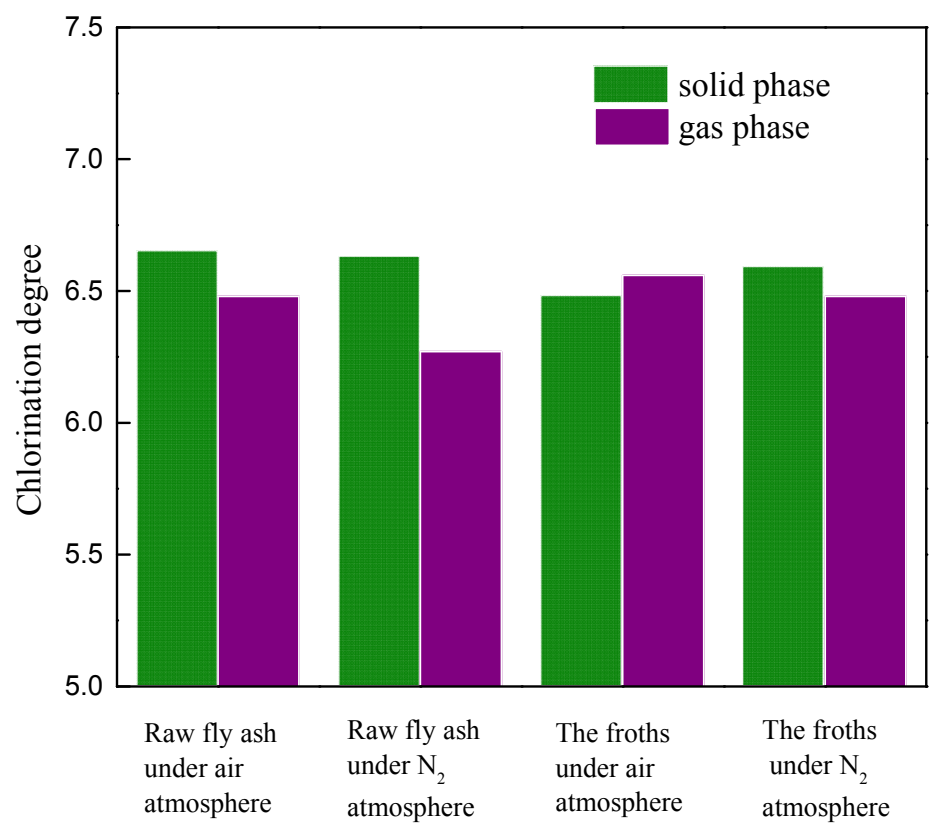

Fig. 10. Chlorination degrees of PCDD/Fs in the raw fly ash and the froths under $\mathrm{N}_{2} /$ air atmosphere.

Certainly, decomposition, volatilization, dechlorination, and/or the de novo synthesis of dioxins in the sample during microwave heating are affected by the way of treatment and the treatment conditions. Influencing parameters including microwave incident power, volume and mass of sample, packing density, air flow rate, and particle size, all require more intensive study. Additionally, heavy metals present in the fly ash may be solidified during microwave treatment, and some volatile heavy metals, such as $\mathrm{Pb}, \mathrm{Zn}$, and $\mathrm{Cd}$, may enter into the exhaust gas.

\section{CONCLUSIONS}

To explore the function of PAC in MWI fly ash during microwave heating, experiments were conducted using froths obtained after flotation and raw fly ash. The temperature changes of PAC surface under a microwave field were also recorded to assess "hotspot" effects of PAC. After treatment with a microwave incident power of $1800 \mathrm{~W}$ for $9 \mathrm{~min}$ in a $\mathrm{N}_{2}$ atmosphere, above $98 \%$ of the dioxins in the froths were decomposed but $65.0 \%$ were decomposed in the raw 
fly ash. The dioxin amounts evaporated from the raw fly ash were significantly higher than those from the froths. This is because large amounts of PAC presented in the froths may accelerate the elimination of dioxins during microwave irradiation. And carbon content in raw fly ash is insufficient to increase the decomposition of dioxins in a short time, thus addition of microwave-absorbing medium into the raw fly ash is necessary. Meanwhile, reaction atmosphere can affect the microwave absorption characteristics of PAC and the dioxin destruction mode. Therefore, dioxins were eliminated much more effectively in $\mathrm{N}_{2}$ atmosphere than that in an air atmosphere. Besides, dechlorinating reactions of dioxins would occur when the raw fly ash was treated in $\mathrm{N}_{2}$ atmosphere.

\section{ACKNOWLEDGMENTS}

The authors gratefully acknowledge Tianjin Natural Science Foundation (18JCYBJC24100), Tianjin Science and Technology Major Project and Engineering (18ZXSZSF0012), National Key Research and Development Program (2017YFC0703100), and National Natural Science Foundation of China (NSFC51378332).

\section{REFERENCES}

Amankwah, R.K., Pickles, C.A. and Yen, W.T. (2005). Gold recovery by microwave augmented ashing of waste activated carbon. Miner. Eng. 18: 517-526.

Antonetti, C., Bonari, E., Licursi, D., Nassi, N.N.O.D. and Galletti, A.M.R. (2015). Hydrothermal conversion of giant reed to furfural and levulinic acid: Optimization of the process under microwave irradiation and investigation of distinctive agronomic parameters. Molecules 20: 21232-21253.

Antonetti, C., Licursi, D., Galletti, A.M.R., Martinelli, M., Tellini, F., Valentini, G. and Gambineri, F. (2016). Application of microwave irradiation for the removal of polychlorinated biphenyls from siloxane transformer and hydrocarbon engine oils. Chemosphere 159: 72-79.

Cha, C.Y. (2001). Process for microwave decomposition of hazardous matter. U.S. Patent No. US 6187988 B1, Feb. 13, 2001. U.S. Patent and Trademark Office, Washington, DC, USA.

Chang, Y.M., Hung, C.Y., Chen, J.H., Chang, C.T. and Chen, C.H. (2009). Minimum feeding rate of activated carbon to control dioxin emissions from a large-scale municipal solid waste incinerator. J. Hazard. Mater. 161: 1436-1443.

Chang, Y.M., Dai, W.C., Tsai, K.S., Chen, S.S., Chen, J.H. and Kao, J.C.M. (2013). Reduction of PCDDs/PCDFs in MSWI fly ash using microwave peroxide oxidation in $\mathrm{H}_{2} \mathrm{SO}_{4} / \mathrm{HNO}_{3}$ solution. Chemosphere 91: 864-868.

Chao, H.R., Lin, D.Y., Chen, K.Y., Gou, Y.Y., Chiou, T.H., Lee, W.J., Chen, S.J. and Wang, L.C. (2014). Atmospheric concentrations of persistent organic pollutants over the Pacific Ocean near southern Taiwan and the northern Philippines. Sci. Total Environ. 491492: 51-59.
Cheruiyot, N.K., Lee, W.J., Mwang, J.K., Wang, L.C., Lin, N.H., Lin, Y.C., Cao, J.J., Zhang, R.J. and Chang-Chien, G.P. (2015). An overview: Polycyclic aromatic hydrocarbon emissions from the stationary and mobile sources and in the ambient. Aerosol Air Qual. Res. 15: 2730-2762.

Cheruiyot, N.K., Lee, W.J., Yan, P., Mwang, J.K., Wang, L.C., Gao, X., Lin, N.H. and Chang-Chien, G.P. (2016). An overview of $\mathrm{PCDD} / \mathrm{F}$ inventories and emission factors from stationary and mobile sources: What we know and what is missing. Aerosol Air Qual. Res. 16: 2965-2988.

Chin, Y.T., Lin, C., Chang-Chien, G.P. and Wang, Y.M. (2012). PCDDF formation catalyzed by the metal chlorides and chlorinated aromatic. Aerosol Air Qual. Res. 12: 228-236.

Chou, S.Y., Lo, S.L. and Hsieh, C.H. (2009). Sintering of MSWI fly ash by microwave energy. J. Hazard. Mater. 163: 357-362.

Chou, S.Y. and Lo, S.L. (2013). Effects of microwaveabsorbing additives on heavy metal immobilization. Environ. Eng. Sci. 30: 317-323.

Dehdashti, A., Khavanin, A., Rezaee, A., Assilian, H. and Motalebi, M. (2011). Application of microwave irradiation for the treatment of adsorbed volatile organic compound on granular activated carbon. Iran. J. Environ. Health Sci. Eng. 1: 85-94.

Han, Y., Liu, W.B., Li, H.F., Lei, R.R., Gao, L.R., Su, G.J. and Liu, G.R. (2017). Gas-particle partitioning of polychlorinated dibenzo- $p$-dioxins, dibenzofurans and biphenyls in flue gases from municipal solid waste incinerators. Aerosol Air Qual. Res. 17: 2847-2857.

Hsieh, Y.K., Chen, W.S., Zhu, J.N. and Huang, Q.L. (2018a). Characterization of polychlorinated dibenzo- $p$ dioxins and dibenzofurans of the flue gases, fly ash and bottom ash in a municipal solid waste incinerator. Aerosol Air Qual. Res. 18: 421-432.

Hsieh, Y.K., Chen, W.S., Zhu, J.N., Wu, Y.J. and Huang, Q.L. (2018b). Health risk assessment and correlation analysis on PCDD/Fs in the fly ash from a municipal solid waste incineration plant. Aerosol Air Qual. Res. 18: 734-748.

Huang, G.Y., Zhao, L., Dong, Y.H. and Zhang, Q. (2011). Remediation of soils contaminated with polychlorinated biphenyls by microwave-irradiated manganese dioxide. J. Hazard. Mater. 186: 128-132.

Hung, N.T., Ting, H.W. and Chi, K.H. (2018). Evaluation of the relative health risk impact of atmospheric PCDD/Fs in $\mathrm{PM}_{2.5}$ in Taiwan. Aerosol Air Qual. Res. 18: 2591-2599.

Hung, P.C., Chen, Q.H. and Chang, M.B. (2013). Pyrolysis of MWI fly ash - Effect on dioxin-like congeners. Chemosphere 92: 857-863.

Jou, C.J.G., Wu, C.R. and Lee, C.L. (2009). Application of microwave energy to treat granular activated carbon contaminated with chlorobenzene. Environ. Prog. Sustainable Energy 29: 272-277.

Kakuta, Y., Matsuto, T., Tanaka, N. and Masuda, T. (2005). Influence of residual carbon on the decomposition 
process of $\mathrm{PCDD} / \mathrm{Fs}$ in MSWI fly ash. Chemosphere. 58: 969-975.

Kim, K.H., Seo, Y.C., Nam, H., Joung, H.T., You, J.C., Kim, D.J. and Seo, Y.C. (2005). Characteristics of major dioxin/furan congeners in melted slag of ash from municipal solid waste incinerators. Microchem. J. 80: 171-181.

Kobylecki, R.P., Ohira, K.J., Ito, I., Fujiwara, N. and Horio, M. (2001). Dioxin and fly ash free incineration by ash pelletization and reburning. Environ. Sci. Technol. 35: 4313-4319.

Lee, K.L., Lee, W.J., Mwangi, J.K., Wang, L.C., Gao, X. and Chang-Chien, G.P. (2016). Atmospheric $\mathrm{PM}_{2.5}$ and depositions of polychlorinated dibenzo- $p$-dioxins and dibenzofurans in Kaohsiung area, southern Taiwan. Aerosol Air Qual. Res. 16: 1775-1791.

Lee, W.S., Chang-Chien, G.P., Wang, L.C., Lee, W.J., Tsai, P.J. and Chen, C.K. (2003). Emissions of polychlorinated dibenzo- $p$-dioxins and dibenzofurans from the incinerations of both medical and municipal solid wastes. Aerosol Air Qual. Res. 3: 1-6.

Lin, L., Yuan, S.H., Chen, J., Wang, L.L., Wan, J.Z. and Lu, X.H. (2010). Treatment of chloramphenicol-contaminated soil by microwave radiation. Chemosphere 78: 66-71.

Lin, X.Q., Ji, L.J., Zhan, M.X., Wang, L.S., Chen, T., Lu, S.Y., Li, X.D. and Yan, J.H. (2018). Suppression of PCDD/Fs by raw meal in cement kilns. Aerosol Air Qual. Res. 18: 1032-1043.

Lin, Y.M., Zhou, S.Q., Shih, S.I., Lin, S.L., Wang, L.C. and Wu, Z.S. (2011). Fate of polychlorinated dibenzo- $p$ dioxins and dibenzofurans during the thermal treatment of electric arc furnace fly ash. Aerosol Air Qual. Res. 11: 584-595.

Lin, Z.R., Zhao, L. and Dong, Y.H. (2013). Application of microwave-irradiated manganese dioxide in the removal of polychlorinated biphenyls from soil contaminated by capacitor oil. Environ. Technol. 5: 637-644.

Liu, H.Q., Wei, G.X. and Zhang, R. (2013). Removal of carbon constituents from hospital solid waste incinerator fly ash by column flotation. Waste Manage. 33: 168-174.

Liu, H.Q., Liu, F., Wei, G.X., Zhang, R. and Zhu, Y.W. (2017a). Effects of surfactants on the removal of carbonaceous matter and dioxins from weathered incineration fly ash. Aerosol Air Qual. Res. 17: 23382347.

Liu, H.Q., Liu, F., Wei, G.X., Zhang, R. and Zang, D.D. (2017b). Two-step flotation treatment for removal of toxic matter from hospital solid waste incinerator fly ash. Aerosol Air Qual. Res. 17: 1329-1340.

Liu, X.T., Zhang, Q., Zhang, G.X. and Wang, R. (2008). Application of microwave irradiation in the removal of polychlorinated biphenyls from soil contaminated by capacitor oil. Chemosphere 72: 1655-1658.

Long, H.M., Li, J.X. and Wang, P. (2012). Influence of dioxin reduction on chemical composition of sintering exhaust gas with adding urea. Cent. South Univ. 19: 1359-1363.

Lundin, L., Aurell, J. and Marklund, S. (2011). The behavior of PCDD and PCDF during thermal treatment of waste incineration ash. Chemosphere 84: 305-310.

Mizukoshi, H., Masui, M., Namiki, N., Kim, J.C. and Otani, Y. (2007). Suppression of solidification of calciumrich incinerator fly ash during thermal treatment for decomposition/detoxification of dioxins. Adv. Powder Technol. 18: 143-154.

Pan, X.C., Yan, J.H. and Xie, Z.M. (2013). Detoxifying $\mathrm{PCDD} / \mathrm{Fs}$ and heavy metals in fly ashes from medical waste incinerators with a DC double arcs plasma torch. J. Environ. Sci. 25: 1362-1367.

Rafalp, K., Kenji, O. and Ichiro, I. (2001). Dioxin and fly ash free incineration by ash pelletization and reburning. Environ. Sci. Technol. 35: 4313-4319.

Rivas, S., Galletti, A.M.R., Antonetti, C., Santos, V. and Parajó, J.C. (2015). Sustainable production of levulinic acid from the cellulosic fraction of Pinus pinaster wood: Operation in aqueous media under microwave irradiation. J. Wood Chem. Technol. 35: 315-324.

Tsai, J.H., Chen, S.J., Li, P.M., Chang-Chien, G.P., Huang, K.L., Tsai, C.H., Hsieh, C.Y. and Lin, C.C. (2018). Characteristics of $\mathrm{PM}_{2.5}$-bound $\mathrm{PCDD} / \mathrm{Fs}, \mathrm{PCBs}, \mathrm{PBDD} / \mathrm{Fs}$ and PBDEs from a diesel generator using waste cooking oil-based biodiesel blends. Aerosol Air Qual. Res. 18: 2583-2590.

Tzanakos, K., Mimilidou, A., Anastasiadou, K., Stratakis, A. and Gidarakos, E. (2014). Solidification/stabilization of ash from medical waste incineration into geopolymers. Waste Manag. 34: 1823-1828.

Wang, L.C., Lee, W.J., Lee, W.S., Chang-Chien, G.P. and Tsai, P.J. (2003). Effect of chlorine content in feeding wastes of incineration on the emission of polychlorinated dibenzo-p-dioxinsydibenzofurans. Sci. Total Environ. 302: 185-198.

Wang, W., Gao, X.B., Zheng, L. and Lan, Y.X. (2006). Reductive dechlorination of polychlo-rinated dibenzo- $p$ dioxins and dibenzofurans in MSWI fly ash by sodium hypophosphite. Sep. Purif. Technol. 52: 186-190.

Wang, Y.F., Wang, L.C., Hsieh, L.T., Li, H.W., Jiang, H.C., Lin, Y.S. and Tsai, C.H. (2012). Effect of temperature and $\mathrm{CaO}$ addition on the removal of polychlorinated dibenzo- $p$-dioxins and dibenzofurans in fly ash from a medical waste incinerator. Aerosol Air Qual. Res. 12: 191-199.

Wei, G.X., Liu, H.Q., Liu, F., Zhang, R., Zhu, Y.W. and Gao, S.Y. (2017). Reburning treatment of the froths obtained after the flotation of incinerator fly ash. Aerosol Air Qual. Res. 17: 1084-1096.

Wei, G.X., Liu, H.Q. and Zhang, R. (2016). Mass concentrations of polychlorinated dibenzo- $p$-dioxins and dibenzofurans (PCDD/Fs) and heavy metals in different size fractions of hospital solid waste incinerator fly ash particles. Aerosol Air Qual. Res. 16: 1569-1578.

Wei, G.X., Liu, H.Q., Zhang, R., Zhu, Y.W., Xu, X. and Zang, D.D. (2017). Application of microwave energy in the destruction of dioxins in the froth product after flotation of hospital solid waste incinerator fly ash. $J$. Hazard. Mater. 325: 230-238.

Wu, H.L., Lu, S.Y., Yan, J.H., Li, X.D. and Chen, T. (2011). Thermal removal of PCDD/Fs from medical waste 
incineration fly ash - Effect of temperature and nitrogen flow rate. Chemosphere 84: 361-367.

$\mathrm{Wu}$, T.N. (2008). Environmental perspectives of microwave applications as remedial alternatives: Review. Waste Manage. 12: 102-115.

Yuen, F.K. and Hameed, B.H. (2009). Recent developments in the preparation and regeneration of activated carbons by microwaves. Adv. Colloid Interface Sci. 149: 19-27.

Zhan, M., Wang, T., Yang, J., Ji, L., Zhou, G., Chen, T., Li, $X$. and Lin, X. (2018). The behaviors and relationships of $\mathrm{PCDD} / \mathrm{Fs}$ and chlorobenzenes in the whole process of one municipal solid waste incinerator. Aerosol Air Qual. Res. 18: 3134-3146.

Zhang, Z.H., Shan, Y.B., Wang, J., Ling, H.J., Zang, S.L., Gao, W., Zhao, Z. and Zhan, H.C. (2007). Investigation on the rapid degradation of congo red catalyzed by activated carbon powder under microwave irradiation. $J$.
Hazard. Mater. 147: 325-333.

Zhang, Z.H., Deng, Y.Q., Shen, M.L., Han, W., Chen, Z.L., $\mathrm{Xu}$, D.P. and Ji, X.T. (2009). Investigation on rapid degradation of sodium dodecyl benzene sulfonate (SDBS) under microwave irradiation in the presence of modified activated carbon powder with ferreous sulfate. Desalination 249: 1022-1029.

Zhu, J.N., Tang, H.Y., Xing, J., Lee, W.J., Yan, P. and Cui, K.P. (2017) Atmospheric deposition of polychlorinated dibenzo-p-dioxins and dibenzofurans in two cities of southern China. Aerosol Air Qual. Res. 17: 1798-1810.

Received for review, December 2, 2018 Revised, March 4, 2019 Accepted, March 5, 2019 